\title{
Analyzing the influence of Climate Change in Brazilian Electricity Markets
}

\author{
Mário Domingos Pires Coelho \\ SES MIT Portugal Program \\ FEUP, CNPQ \\ Porto, Portugal \\ mariucoelho@yahoo.com.br
}

\author{
João Tomé Sariava \\ INESCTEC and DEEC \\ FEUP \\ Porto, Portugal \\ jsaraiva@fe.up.pt
}

\author{
Adelino Jorge Coelho Pereira \\ IPC/ISEC - Instituto Superior de \\ Engenharia de Coimbra, \\ Coimbra, Portugal \\ ajcp@isec.pt
}

\begin{abstract}
The Brazilian Power System is mostly supplied by hydro-generation. In this context there is a strong connection between rain-fall regimes and the Electricity Prices in the short term market. This work describes the main features, developments and functioning of a System Dynamics model that simulates the four Brazilian short term electricity submarkets Based on studies reporting the change in rainfall regimes in Brazil due to Climate Change, we analyze the impacts of these changes in each specific region and in the electricity markets as a whole. The results provide good insights on the impacts of Global Warming in the Brazilian Power System, indicating for instance that the Southeast/Center-West Electricity Submarket is the one that will be most affected by the global issue in terms of rise in the electricity prices.
\end{abstract}

Index Terms-- Climate Change, Electricity Markets, Long-term analysis, System Dynamics.

\section{INTRODUCTION}

In many countries the Electricity Sector has gone through deep changes in the recent years that correspond to a change of the paradigm that was long associated to power systems. The main drivers for these changes are the introduction of competitive mechanisms, the unbundling of the electricity sector, the renewable energy deployment, the improvement on computer and communication technologies and the larger role that has been progressively assigned to end consumers. These elements are quickly reshaping the way power systems are regulated, operated and planned.

Firstly, changes affected the way electricity is delivered to the consumers namely from a commercial point of view. Electricity used to be treated as a public service delivered and regulated as a natural monopoly, whereas in most part of the western world it was controlled by public utilities. However, since the late decades of the XX Century, the liberalization of the sector introduced competition mainly in the generation and retailing activities, completely changing the way in which Power Systems are organized [1].

From the perspective of the generation technologies, Climate Change concerns and the need to become more independent from Fossil Fuels in many countries, triggered the investment and deployment of technologies that weren't economically feasible in the near past. The investments on Wind Power and on Solar PV along time contributed to strongly reduce the investment costs of these technologies thus enabling their larger deployment and therefore introducing new features on Power System operation and planning.

The other driver of the changes in the sector is the evolution on computational and communication facilities as well as technical developments in new generation technologies. With the rapid increase of these technologies more control, flexibility and information is available and can be treated in real time, enabling larger gains on efficiency and the development of micro grids and distributed generation [2].

These facts are introducing a new paradigm on the electricity sector. Under this new framework, the scope of the planning activities is being changed, increasing the number of dimensions, uncertainties and the complexity of the problems to be addressed. Furthermore, new objectives and constraints, mainly regarding environmental and GHG emissions are increasingly changing the way the sector is planned, developed as well as introducing new challenges in its operation and control.

Taking into account these recent developments, this paper describes a System Dynamics, SD, based tool developed to perform long term expansion planning studies. In this case, this paper addresses the use of the developed SD model to investigate the impacts of Climate Change in the prices of the Brazilian electricity market in the medium and in the long run. This SD model was already successfully used to perform analysis regarding the transmission bottlenecks among several regions in which the Brazilian power system is organized, as well as to access the impacts of Wind Power on the electricity prices in these regions as reported in [3].

Apart from this Introduction, Section II includes a brief overview of the drivers of the changes in the Electricity Sector, providing also information on how models and planning tools are being adapted in order to accommodate these changes. Section III describes the main features of the developed SD model and its tuning to take into account the characteristics of the Brazilian Power System. Section IV describes the simulations that were performed, the

The first author thanks the National Council of Scientific and Technological Development, CNPQ, for funding this work. 
corresponding results as well as their discussion and analysis. Finally, Section V provides the main conclusions of this research.

\section{DRIVERS OF CHANGE/DRIVERS OF THE REVOLUTION}

As previously mentioned, there are many factors influencing the way in which power systems are currently organized. In this section we are focusing on the liberalization of the sector and the introduction of competitive mechanisms in several activities market, on the technology deployment and on the impact of Climate Change in power systems.

\section{A. Unbundling of the Electricity Sector - why using System Dynamics}

The unbundling of the electricity sector introduced a new dynamic in the sector namely due to the development of electricity markets. Under the traditional monopolistic framework, utilities were able to set up their investment schedule in a larger time-frame. They were responsible for building generation, transmission and distribution facilities, and their remuneration was based on the investment, maintenance and operation costs of the required infrastructures. In this framework, expansion planning activities consisted on optimizing the costs to identify the most adequate option among the investment possibilities. During this period, many methods were developed to perform long term expansion planning activities mainly applying mixed integer, dynamic, and linear and nonlinear programing with several kinds of optimization algorithms and heuristics. As mentioned in [4], in these traditional approaches decision trees and multiobjective techniques were used less frequently.

However, as the sector was unbundled and competition was introduced, the dynamics of the price formulation and investments schedule changed from a cost optimization context to a market oriented one. In the market framework, agents compete among themselves and the price formation is given by the equilibrium between demand and supply. In this scope a completely new set of tools and approaches started to be used in power systems studies like Agent Based Models [5] and System Dynamics [6]. In Agent Based Models market participants are modeled independently and behave somehow stochastically according to a pre-defined set of rules. This generates some of the dynamics and randomness observed in the real world. Models that use System Dynamics are more concerned about the inter relations that exist among the variables and typically include feedback loops through which one variable influences the other.

\section{B. Deployment of new generation technologies - why and how they can be modelled and addressed}

The Electric Power Industry in the $20^{\text {th }}$ century was mainly based on hydrothermal technologies. Electricity was generated in large hydro and thermal power plants, in which the main fuels were coal, oil, natural gas and nuclear. In this context, the management of the Electricity Sector was simpler and utilities generated as much hydropower as possible and used the other (and more expensive) thermal power plants in order to meet the demand. However, the oil crisis in the 1970's triggered the beginning of investments in new and alternative energy sources. In Brazil for instance, this triggered the investments in the Pró Álcool Program, that was designed to induce the production of Ethanol from sugar cane in order to reduce the oil dependence. Later on, during the 1990's the issue of Climate Change, together with the new oil crisis during the Gulf War, emphasized the necessity of energy independence all over the world, fostered the investment in new generation technologies like wind power on and off-shore and solar PV. Back in 2002, European Countries, mainly Germany, Spain and Denmark, held the large amount of the $27260 \mathrm{MW}$ of installed wind turbines in the world [2]. As by the end of 2015, the total installed solar PV capacity reached $227 \mathrm{GW}$ while the total wind power capacity is larger than 433 GW [7].

As these new technologies occupy a larger amount of the Electric Matrix in several countries, the complexity of Power Systems operation and planning activities are increased. Since these sources have intermittent nature, a larger degree of uncertainties are involved in the operation of the system, what increases the need for more on line information, for more control tools so that a quicker response to real time events can be obtained and the security of supply is maintained.

Concerning energy planning, the rapid cost reduction of these sources makes it really difficult to foresee how large will be their influence in the Power System in the future namely in view of the existing competitive electricity market framework. Therefore, new and more flexible tools are needed in order to better understand, anticipate and plan the Power Systems of the future. In this context, the System Dynamics tool that is used in this research aims at providing a broader comprehension of the influence of these changes and uncertainties in the Electric Sector of the future while enlarging the flexibility of the system to accommodate these new sources and ensuring the same degree of robustness and security of supply.

\section{Climate Change - why is this important and what will its impacts be}

The Climate Change is a reality that is every year more tangible and sensible for all the society and scientific community. Quoting [8] "The number of papers rejecting AGW [Anthropogenic, or human-caused, Global Warming] is a miniscule proportion of the published research, with the percentage slightly decreasing over time. Among papers expressing a position on AGW, an overwhelming percentage ( $97.2 \%$ based on self-ratings, $97.1 \%$ based on abstract ratings) endorses the scientific consensus on AGW."

After NASA classified the years of 2015 and 2016 as the warmer years on the whole history and the consequences of Global Warming started to be felt more intensively, more studies are needed to better evaluate the influence of the issue on the planet and in our society.

In this context, the Center for Management and Strategic Studies from Brasilia University published a study in order to access in a broader perspective the impacts of Climate Change in several geographic areas and biomes [9]. On the other hand, researchers from the Federal University of Rio de Janeiro (UFRJ) conducted a specific research on how Global Warming will affect the Energy Security [10]. This study used 
the projections for the Brazilian Energetic Matrix by 2030 (obtained in the National Energy Plan [11]) and estimated the rain fall and the flows in the rivers considering the temperatures and climate forecast for the year 2100, provided in the Intergovernmental Panel on Climate Change (IPCC) Report [12]. This study foresees a decrease in the average water inflows from $8.6 \%$ to $10.8 \%$ in the whole country.

This decrease in the rain flows is likely to have a strong influence on the electricity markets namely in countries where the energy matrix is currently more dependent on it, as it occurs in Brazil. In this work we aim to quantitatively access this influence by applying the developed SD model to the Brazilian Power System. This application involves running simulations admitting that the hydropower availability is reduced in the long term so that it becomes possible to estimate the impacts on the electricity prices.

\section{The BRAZILIAN POWER SySTEM MODEL USING SYSTEM DYNAMICS}

\section{A. Overview of the developed SD model}

In this section we provide an overview of the Brazilian Electricity Sector and explain how the SD developed model works in order to mimic the real world functioning. As stated before, the model was already used in case studies regarding other issues as transmission bottlenecks and renewable energy sources penetration [13]. However, new improvements were recently introduced in order to expand the boundaries and capabilities of the model.

The Brazilian Electricity Market is divided into four different electricity submarkets, because of the different energy sources that are available in each geographic region and also due to the transmission constraints between these regions. The four electricity submarkets are the South, Southeast/Center-West (which we will call SECO), Northeast and North as indicated in Fig. 1.

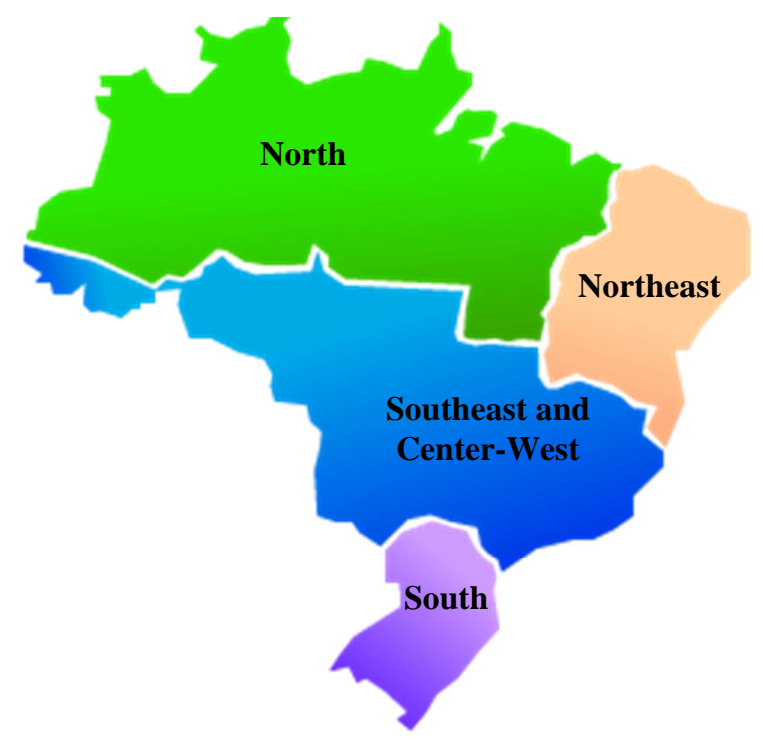

Figure 1. Geographic organization of the Brazilian Power System (adapted from: www.ccee.org.br)
In [3] and [13] the Brazilian Power System was modelled with only two subsystems, by combining the South and the SECO submarkets, on one side, and the North the Northeast subsystems, on another one. In this paper the model was enhanced and expanded, so that each of the subsystems is now represented with its own features. The main characteristics of each Submarket are displayed in Table I as their geographic distribution is displayed in Fig. 1. The complete model is formed by modules representing each of the existing submarkets in Brazil. In each of these four modules, there are structures representing generation, demand and the price formation of each submarket. Fig. 2 provides a screen-shot of the Northeast Module that is integrated in the global model developed using the Powersim Software [14]. The transmission of electricity between the four mentioned regions is also considered in order to dispatch the less expensive resources. Then the final dispatch and the prices within the country are settled.

\section{B. Structure of the developed SD model}

In each of the subsystems there is a representation of the generation assets formed by the hydro (highlighted in blue in Fig. 2), thermal (in red) and wind (in green) facilities. The demand is represented by a separate structure (in orange). The price (in the middle of the structure in Fig. 2) is then calculated in each time step, based on the relation between supply and demand. Moreover, considering the transmission capabilities (highlighted in yellow) and the price difference between the regions, it is defined the quantity of energy to be transmitted between pairs of regions physically connected.

The main formulation and logic of each module is detailed in [3] and remains the same. The structures that were modified in their formulation are related with the hydropower and the price variation. In the previous formulation all the energy flowing in the rivers, $E N A_{t}$, which is represented in the screen shot by the variable 'energy flow NE', would be stored in the reservoirs of the subsystem. The Reservoirs are represented in the stock structure 'Reservoir NE' in the picture. This formulation does not take into account the possibility of spillage. In the currently available model we are now considering a maximum limit for the energy stored in the reservoirs, $\operatorname{Res}_{\operatorname{Max}}$, and when this limit is reached all the additional water that flows into the reservoirs is spilled. This logic is introduced in the module portrayed in Fig. 2 with the new structures above the stock variable 'Reservoir NE'. A new flow was inserted, 'spillage NE', in addition to the ones previously designed. The logic implemented compares the current reservoir level with the maximum level, which is yearly updated, and if the level reaches its maximum, extra water is spilled.

Regarding the data provided in Table I, it allows clarifying better the functioning of the model. The Energy Flow, represented as the input 'INPUTS ENERGY FLOW NE' in Fig. 2, is inserted in the model according to the monthly water flow patterns. Therefore, the model considers the seasonal variability of the rivers. The Maximum Res Capacity, Installed Thermal Capacity and Installed Wind Capacity are updated in a yearly basis, to represent the expansion of the system. They are inserted in the variables, 'MAX RESERVOIR NE', 'THERMAL POWER NE' and 'WIND POWER NE'. 
TABLE I. MAIN FEATURES OF THE BRAZILIAN SUBSYSTEMS

\begin{tabular}{|c|c|c|c|c|c|}
\cline { 2 - 5 } \multicolumn{1}{c|}{} & $\begin{array}{c}\text { Annual } \\
\text { Average } \\
\text { Energy Flow }\end{array}$ & $\begin{array}{c}\text { Maximum Res } \\
\text { Capacity }\end{array}$ & $\begin{array}{c}\text { Installed Thermal } \\
\text { Capacity }\end{array}$ & $\begin{array}{c}\text { Installed } \\
\text { Wind } \\
\text { Capacity }\end{array}$ & Initial Demand \\
\hline South & $9245 \mathrm{MWave}$ & $14592 \mathrm{GWh}$ & $3500 \mathrm{MW}$ & $3600 \mathrm{MW}$ & $1773 \mathrm{GWh} / \mathrm{week}$ \\
\hline SECO & $34640 \mathrm{MWave}$ & $149722 \mathrm{GWh}$ & $11377 \mathrm{MW}$ & $4 \mathrm{MW}$ & $6136 \mathrm{GWh} / \mathrm{week}$ \\
\hline Northeast & $8146 \mathrm{MWave}$ & $37887 \mathrm{GWh}$ & $5920 \mathrm{MW}$ & $12500 \mathrm{MW}$ & $1607 \mathrm{GWh} / \mathrm{week}$ \\
\hline North & $7445 \mathrm{MWave}$ & $10820 \mathrm{GWh}$ & $4028 \mathrm{MW}$ & $0 \mathrm{MW}$ & $863 \mathrm{GWh} / \mathrm{week}$ \\
\hline
\end{tabular}

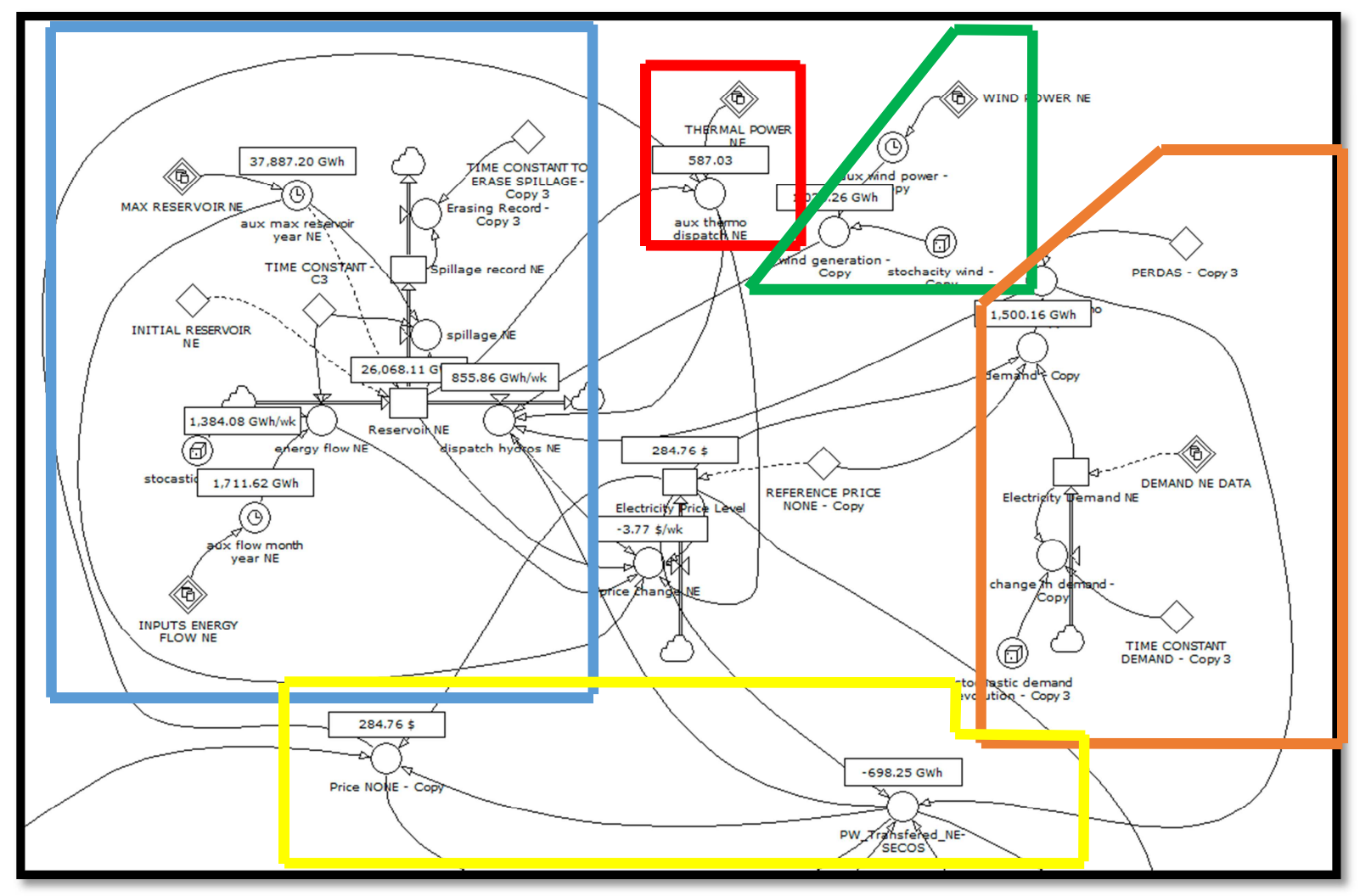

Figure 2. Screen-shot of the Northeastern Subsystem built in the Powersim Software.

The new formulation adopted for Reservoir, $\operatorname{Res}_{t}$, is based on the energy flowing, the dispatched hydropower, $P_{H y, t}$, and the spillage, $S p_{t}$, and it is given by (2).

$$
\begin{aligned}
& \operatorname{Res}_{t}=\int\left(E N A_{t}-P_{H y, t}-S p_{t}\right) \cdot d t \\
& \mathrm{Sp}_{\mathrm{t}}=\max \left(0 ; \operatorname{Res}_{t}-\operatorname{Res}_{\mathrm{Max}}\right)
\end{aligned}
$$

Regarding the price formulation, a new dynamic was observed when the four submarkets were separated. As some of the regions are typically importing electricity whereas others are exporting, the Reservoirs can be spilling in many occasions namely because of transmission bottlenecks that may exist between the regions. In order to address this issue, a new price formulation was introduced, so that the prices would decrease quicker when the Reservoirs are full. Thus, the price at time $t, \pi_{t}$, depends on the price at time zero, $\pi_{0}$, and the price variation index, $\Delta \pi_{t}$. The variation $\Delta \pi_{t}$ is calculated considering some of the variables mentioned before together with the dispatched thermal power $P_{t h, t}$. The new implemented formulation is then given by (3) and (4). In this new formulation we inserted the term, $\left(1-\left(\operatorname{Res}_{t} / \operatorname{Res}_{\text {Max }}\right)\right)$, as a multipliers of the thermal power dispatched. By inserting this term, we aim at guarantying that in periods in which the prices are high (which means that the dispatched thermal power is large), but there is Hydro Power availability (energy in the Reservoirs approaching the maximum level) the positive influence of the thermal power on prices will decrease.

$$
\begin{aligned}
& \pi_{\mathrm{t}}=\pi_{0}+\int_{0}^{\mathrm{t}} \Delta \pi_{\mathrm{t}} \cdot \mathrm{dt} \\
& \Delta \pi_{\mathrm{t}}=\pi_{\mathrm{t}} *\left[\frac{\mathrm{P}_{\mathrm{Hy}, \mathrm{t}}-\mathrm{ENA}_{\mathrm{t}}+\left(\mathrm{P}_{\mathrm{th}_{\mathrm{t}} *\left(1-\left(\operatorname{Res}_{t} / \operatorname{Res}_{\text {Max }}\right)\right)}\right.}{\operatorname{Res}_{t}}\right]
\end{aligned}
$$

\section{Consideration of transmission limits between regions}

The expansion of the model from two subsystems into four required modifications in the transmission module that will now be highlighted and explained. In the previous model the transmission flow between the two subsystems, Trans, was calculated considering the price difference between both of the regions, that is, the electricity price in the North, $\pi_{N}$, and the 
electricity price in the Northeast, $\pi_{N E}$. The basic idea is that the larger the difference of prices is, the larger amount of electricity would be transferred between the regions, so that prices could reach an equilibrium and energy could be transferred from cheaper region to the more expensive one. This logic is maintained respecting the physical connections and constraints. Therefore, the adopted formulation is portrayed below, using the example for the North and Northeast Subsystems. In (5) $\operatorname{Trans}_{N, N E}$ is the electricity transmitted between the North and the Northeast regions and it obtained as the fractional price difference between them multiplied by the sum of the demand in the North, $\operatorname{Dem}_{N}$, and in the Northeast subsystem, Dem $m_{N E}$,. Naturally, the transmission capacity limit between these regions is also

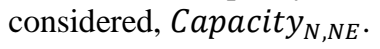

$$
\begin{array}{r}
\operatorname{Trans}_{N, N E}=\left[\frac{\pi_{N}-\pi_{N E}}{\operatorname{Min}\left(\pi_{N} ; \pi_{N E}\right)}\right] *\left(\operatorname{Dem}_{N}+\operatorname{Dem}_{N E}\right) \\
\text { s.t. } \operatorname{Trans}_{N, N E} \leq \text { Capacity }_{N, N E}
\end{array}
$$

Thus, as the transmission of electricity also influences the generation formulation, whenever new transmission connections between pairs of regions are built and become available, the dispatch is also changed. For instance, the Hydropower dispatch, $P_{H y, t}$ in the Southeast/Center-West subsystem, which is connected to all the other subsystems of the country, is then a function of the Demand in the region, Dem $_{S E C O}$, the Wind Power generated in the region,
$P_{w, t}$, the dispatched thermal power $P_{t h, t}$, and the power transferred from/to all the neighbor areas as indicated in (7).

$$
\begin{aligned}
& \mathrm{P}_{\mathrm{Hy}, \mathrm{t}}=\text { Dem }_{\mathrm{SECO}}-\mathrm{P}_{\mathrm{w}, \mathrm{t}}-\mathrm{P}_{\mathrm{th}, \mathrm{t}}+\text { TransSECo,NE }+ \\
&+ \text { TransSECo,N }+ \text { Trans } \\
& \text { SECO,S }
\end{aligned}
$$

As observed in Figure 1, the SECO subsystem is the one that has physical and transmission connections to all the other subsystems in the country while the South sub system only has connections to the SECO region. Therefore, it is expected that changes in the SECO subsystem will be more intensively spread and felt in all the other subsystems. The other way round it is also true and it will be observed when analyzing the results in the next section. In the tests to be described in the next section, droughts were simulated by reducing the amount of energy flowing in the rivers. With this kind of analysis we expect that both the Government and private agents of the Electricity Market can obtain deeper insights concerning the risks and the impacts that Climate Change will have in the electricity prices and in the electricity sector in general.

\section{RESUlTS AND DISCUSSION}

The tests were performed by simulating droughts in each of the four subsystems, with a time step of one week, for the years from 2016 until 2025. This was simulated reducing the flows in each of the subsystems by $10 \%$, following the forecasts provided in [9]. By doing this we obtained the results

\begin{tabular}{|c|c|c|c|c|}
\hline \multirow[b]{2}{*}{ Case Under Study } & \multicolumn{4}{|c|}{ Average Electricity Prices Over the Simulation Period } \\
\hline & South & SECO & Northeast & North \\
\hline Reference Scenario (€/MWh) & 62.95 & 62.83 & 60.18 & 56.20 \\
\hline \multirow{2}{*}{$\begin{array}{l}\text { Droughts in SECO Region (€/MWh) } \\
(\% \text { Variation regarding the base case) }\end{array}$} & 69.86 & 69.94 & 66.22 & 61.34 \\
\hline & 10.99 & 11.31 & 10.03 & 9.16 \\
\hline \multirow{2}{*}{$\begin{array}{l}\text { Droughts in North Region }(€ / \mathrm{MWh}) \\
(\% \text { Variation regarding the base case) }\end{array}$} & 63.93 & 63.35 & 60.73 & 58.21 \\
\hline & 1.56 & 0.82 & 0.91 & 3.59 \\
\hline \multirow{2}{*}{$\begin{array}{l}\text { Droughts in Northeast Region (€/MWh) } \\
(\% \text { Variation regarding the base case) }\end{array}$} & 64.95 & 64.56 & 62.45 & 57.69 \\
\hline & 3.18 & 2.76 & 3.76 & 2.66 \\
\hline \multirow{2}{*}{$\begin{array}{l}\text { Droughts in South Region (€/MWh) } \\
(\% \text { Variation regarding the base case) }\end{array}$} & 67.63 & 66.77 & 63.37 & 58.78 \\
\hline & 7.43 & 6.27 & 5.30 & 4.60 \\
\hline \multirow{2}{*}{$\begin{array}{l}\text { Droughts in all the Regions (€/MWh) } \\
(\% \text { Variation regarding the base case) }\end{array}$} & 73.44 & 72.40 & 69.14 & 65.60 \\
\hline & 16.67 & 15.23 & 14.87 & 16.72 \\
\hline
\end{tabular}
presented on Table II. In the following sections the results of the simulations will be presented and discussed.

TABLE II. RESULTS OF THE SIMULATIONS (PRICES IN €/MWH AND \% INCREASE REGARDING THE REFERENCE SCENARIO)

\section{A. Droughts in the SECO subsystem}

As observed, the occurrence of droughts in the SECO region causes a more severe impact in terms of raising the electricity prices in all the subsystems. In fact, reducing the hydroelectric availability by $10 \%$ originated a price increase of more than $10 \%$ comparing to the reference case. This fact can be explained because the SECO region corresponds to the larger load and generation center in the country, having a strong importance in shaping the Power System operation in general. Moreover, as the SECO subsystem is in the center of the country, it has strong transmission connections with all the other subsystems, and this fact facilitates spreading the effect of the drought and rising prices to the other regions.

\section{B. Droughts in the North subsystem}

The North subsystem is the one that suffers fewer impacts in the overall system. On one side, it has the smaller amount of hydropower installed capacity and, from the other, it has the lowest demand among all the subsystems. Additionally, it should be highlighted that the North subsystem in all the evaluated scenarios can be characterized as an exporter of electricity so that in all the analyzed situations the electricity prices stayed lower than on the other regions.

As a result, reducing by $10 \%$ the hydropower availability caused only $3.59 \%$ of price increase in the region and impact of these drought conditions on the other regions are less than $2.0 \%$. 


\section{Droughts in the Northeast subsystem}

The Northeast subsystem when affected by drought conditions suffers an impact on the electricity price of $3.76 \%$. This subsystem has a similar hydropower capacity as in the North system, which means that in general the effect in the electricity prices were expected to be similar to the ones in the North subsystem. However, the demand level in the Northeast is larger than in the North subsystem which explains why a similar reduction of energy availability originates a larger impact. In any case, as indicated in Table I the installed wind power capacity in the Northeast subsystem contributes to soften this effect.

\section{Droughts in the South subsystem}

The South subsystem is less integrated with the other subsystems only having connections with the SECO Region. Therefore, the effects of the droughts in the South are observed as a cascade of impacts. In fact, having a drought in the South causes a price increase of $7.43 \%$ in the South, $6.27 \%$ in the SECO Region, $5.30 \%$ in the Northeast and $4.6 \%$ in the North Region. This is a nice contrast regarding the result observed in the first case because droughts in the SECO subsystem are almost equally spread through all the adjacent subsystems.

\section{E. Droughts in all the subsystems}

The Climate Change is expected to cause different effects in the regions of the country. In this scope [9] indicates that the mean value of the reduction in the average flows in all Brazilian water basins would be around $10 \%$. Thus, in the last simulation we admitted that the flow reduction was applied to all the subsystems. The results indicate that if a drought condition is spread all over the country, this would cause in average an electricity price increase of $15.8 \%$ over the planning period. It is interesting to highlight that in this simulation the ratio/relation between the electricity prices between the regions is maintained almost the same as in the reference scenario. This is an indication that the electricity prices are kept with the same relative balance, when the electricity matrixes and the ratios of renewable and nonrenewable sources are kept similar within the subsystems.

\section{CONCLUSION}

In this paper, we analyzed the impact of Climate Change in the Brazilian Electricity Market namely considering drought situations in the different subsystems. The country recently faced a sequence of years (2012-2015) with serious droughts that caused large consequences in the Electricity Sector, being the Climate Change appointed as the major cause for these situations. In this scope, we used a SD model applied to the Brazilian Power System to conduct a series of tests to quantitatively characterize how the droughts foreseen in other studies will impact the Brazilian Electricity Market. In these simulations, we observed that the Southeast/CenterWest Region, SECO, of the country is the one most vulnerable to climate change. This region has the largest electricity generation and demand and it is the one that has connections with all the other regions. As a result, the reduction of water flows in this region will impact more intensively in the entire system originating price increases from 9 to $11 \%$ all over the country. With the simulations we managed to order the regions of the country considering the impacts of the climate change in the electricity prices as follows: the SECO is the most affected one, followed by the South, the Northeast and the North regions.

This information and the quantification of the expected price impacts can be very useful to planners and governmental agencies in order to help them to adequately plan the system expansion in order to minimize these impacts while coming with more robust decisions. For instance, promoting specific tenders of new power plants located in SECO region, which is the most affected by the Climate Change, could increase the social welfare. As another example, the reinforcement of specific transmission connections, as the ones between South and SECO, could provide a more global benefit then new power plants, in view of future adverse weather scenarios.

\section{ACKNOWLEDGMENT}

The first author acknowledges the League of System Dynamics in the University of Bergen for the fruitful contributions in the deployment of the work.

\section{REFERENCES}

[1] J. T. Saraiva, M. T. Leão, J. L. Silva (2002). Electricity Markets Regulation and Network Tariffs. (in Portuguese). FEUP Edições, Porto, Portugal.

[2] J. A. Peças Lopes, N. Hatziargyriou, J. Mutale, P. Djapic, N. Jenkins, "Integrating distributed generation into electric power systems: A review of drivers, challenges and opportunities", Electric Power Systems Research, vol. 77, no. 9, pp 1189-1203, July 2007.

[3] M. D. P. Coelho, J. T. Saraiva, A. J. C. Pereira, "Long Term Expansion Planning of the Brazilian Generation System Using Dynamic Systems", presented at the 51st International Universities Power Engineering Conference, UPEC 2016, Coimbra, Portugal, in press.

[4] B. F. Hobbs, "Optimization methods for electric utility resource planning", European Journal of Operational Research , vol. 83, no. 1, pp. 1 - 20, May 1995.

[5] A. Weidlich, D. Veit, "A critical survey of agent-based wholesale electricity market models", Energy Economics, vol. 30, no. 4, pp. 17281759, July 2008.

[6] J. D. Sterman, Business Dynamics: Systems Thinking and Modeling for a Complex World, Irwin/McGraw-Hill, 2000, Boston.

[7] Renewables 2016, "Global Status Report", Paris, Ren21 Secretariat; Available on line at: www.Ren21.net;

[8] J. Cook, et al, "Consensus on consensus: a synthesis of consensus estimates on human-caused global warming", Environmental Research Letters, vol. 11, No. 4, April 2016, DOI: 10.1088/17489326/11/4/048002

[9] Centro de Gestão e Estudos Estratégicos, "Subsides for a National Agenda of Science, Technology and Innovation regarding the vulnerability, impacts and adaptation on Climate Change" (in Portuguese), Brasília, 2008.

[10] R. Schaeffer, et al. "Climate Change and Energy Security in Brazil", (in Portuguese). Rio de Janeiro: Nova Brasileira, 2008. 67 p.

[11] Ministério de Minas e Energia / Empresa de Pesquisa Energética, "National Energy Plan 2030" (in Portuguese), Brasília, 2007.

[12] 2014 Intergovernmental Pannel on Climate Change, IPCC SYNTHESIS REPORT, available on line at: http://www.ipcc.ch

[13] M. D. P. Coelho, J. T. Saraiva, A. J. C. Pereira, "Long Term Impacts of RES-E Promotion in the Brazilian Power System", unpublished, accepted to be presented at PowerTech 2017, Manchester, UK, June 2017.

[14] L. A. Malczynski, "Best Practices for System Dynamics Model Design and Construction with Powersim Studio", Prepared by Sandia National Laboratories, 2011. Available online at: http://www.powersim.com/main/services/simulation_services/user co mmunities/white-papers/powersim-studio-best-practices-manual/ 
